\title{
Concept of the service-digital approach to the management of engineering systems of buildings
}

\author{
Vasily Zharov ${ }^{1 *}$, and Nikolai Komarov ${ }^{2}$ \\ ${ }^{1}$ Cand. Sc. Engineering, Senior lecturer of High School of Service Federal State Budgetary \\ Educational Institution of Higher Education RGUTIS, Russia \\ ${ }^{2}$ Doctor of Engineering Science, Professor of Federal Unitary Enterprise "All-Russian Scientific \\ Research Institute "CENTER”, Russia
}

\begin{abstract}
The problem being reviewed in this article is quite complex and represents a combination of economic, technical, organizational, managerial relations in the management of the engineering systems of the real estate objects that arise in the process of forming a new technological paradigm in the context of growth of the digital economy. The article demonstrates that service activities cover a significant area of social relations associated with development, production and provisions of various types of services including the field of real estate. The study focuses on life cycle contracts for energy supply and it is shown that they are an integral part of the engineering systems management processes. The thesis is given that the service becomes an integral part of the good and the good becomes an integral part of the service. It is demonstrated that operation of the real estate objects including various intelligent buildings consists of various types of services which in one form or another are services by their nature - the services for maintaining the object in operative condition, the services for supplying the object with various resources, the services for maintaining the engineering systems of the object etc. It is shown the relationship between the processes of the real estate objects management and the processes related to the services actives. It is proposed to use the approaches of the systems engineering and the complex engineering in order to solve the tasks related to the management of the engineering systems.
\end{abstract}

\section{Introduction}

The service activities as one of the most important field of the business activities cover a significant area of social relations associated with development, production and provision of various types of services including the field of real estate.

Many researchers including the researches $[1,2,3,4]$ point out that there is a growing role of the service sector in the economic processes of the different countries of the world from Europe to Asia which is a leading sector of the national economy and one of the most important sphere of the human social life.

* Corresponding author: basille@mail.ru 
Representatives of the scientific community agree that activities in the service sector are based on the structuring of the service process, its optimization in order to make it more convenient for the customer. According to various sources of the information it is established that development of the market relations and existence of the free competition forces more attention to the quality of the provided services and the requirements that have come relevant and which this article is devoted to. [1, 2, 3, 4]

As the authors of this article point out which was also noted in the research [5] a sustainable growth of the digital economy and the corresponding innovative processes are observed. Under these circumstances we can notice the trend in which the consumers of a number of goods become simultaneously the consumers of the related services Thus, for example, the use of a product, a real estate object, is not possible without the consumption of community facilities as heating, electricity, water supply and wastewater disposal, the Internet and telephony, security and warning, and others, without these services a product, a real estate object, is unable to demonstrate its properties and its full-scale use becomes impossible.

One of the key parts in solving this problem is the after-sale support of goods and services (life cycle contracts) provided by a particular company, resource-supplying organization since the service provision is required within the entire life cycle of a sold product or service. Life cycle contracts for energy supply services are an integral part of processes of the engineering systems management of the real estate objects. In this case we can say that the service becomes an integral part of the good and the good becomes an integral part of the service. $[6,7]$

The service activity in the digital economy has a number of innovative approaches which allow providing the customer with different types of services virtually, remotely and with the involvement of real specialists - service engineers. The more complex the engineering systems of the real estate object is the higher qualification of the service specialist should be. [5]

Taking into consideration the above aspects related to the modern realities of the economy digitalization it is appropriate to speak about the innovative service-digital approach to the management of engineering systems of the real estate objects. [8]

Currently real estate objects are used for the needs of the national economy in all their variety based on the existing classification according to different criteria. A common characteristic of all, without any exceptions, real estate objects will be the availability of the engineering systems which ensure the functioning of these buildings in accordance with the goals of the operation. It is reasonable to say that each real estate object has the owner who is looking to minimize its operational expenses. Engineering systems are the most costly part since their functioning is associated with consumption of energy resources so the management of engineering systems of the buildings can also be considered not only as a managerial but also as a problem of energy saving. [8,9]

The engineering system of the building can be described as a technically complex system which consists of a large number of interconnected components and assemblies ensuring the functioning of the system as a whole. [10]

Depending on the purpose of the building, peculiarities of its operation and modern requirements for real estate objects the engineering systems can be bound into a unified complex controlled by a central dispatching point. Such buildings are called "Intelligent buildings".

The intelligent building is "a building that ensures productive and efficient use of working space". In the 70-s of XX century such definition was given by Intelligent Building Institute located in the capital of the USA, Washington, not to the building itself but to the approach to the management of the engineering systems and principles which were laid down at the stage of the building design. [10,11] 
In addition to the above name one can find in the literature the definition - abbreviation BACS (Building Automation and Control System). This definition can be often met in the characteristics of the commercial real estate object, the industrial building. The goal of the integration of any automation system is to optimize the expenses on the real estate object operation, reduce the risk associated with the human factor, reduce the response time to emergencies, provide control over resources consumption and automatically transmit the meter reading to the processing data centers. This approach can be described as an innovative one with the use of the digitalization capabilities and the service-digital approach towards the management of the buildings engineering systems. [11, 12]

According to the results of the research [12] we can say that the implementation of the above approach to the operation of the real estate objects has the potential to reduce the operational costs up to $65 \%$. Moreover, it was observed that if the operating mode of the equipment in the engineering systems of the building is within the range of the optimal values which is supported by the service-digital approach then the failure-free service life of such equipment can be increased up to $50 \%$.

However, it is worth mentioning that operational reliability of all systems of the building is a result of a rapid response to an emergency situation both from the automation and the dispatchers - specialists with the relevant competencies who received the immediate notification of an accident. [11]

The consumer is keen on everything new and innovative, therefore, except the above name "Intelligent building" there is also a term "Smart house". First of all, "Smart house" is not the house itself, not the shell but a control system to which the systems of the real estate object can be connected: heating, water supply, electricity, ventilation and air conditioning, security systems and others governed by a single dispatching point. We can say that "Intelligent building" and "Smart house" essentially mean the same thing - the object with the engineering systems controlled by a single dispatching center. In the literature "Smart house" is used more often for description of the characteristics of the residential buildings, individual households, meanwhile, "Intelligent building" is for description of commercial objects. [12]

The development of the digital technologies is extremely fast, that is why we are observing a qualitative leap from the basic technologies that cannot be integrated into a single control system to the complex microprocessor-based programmable innovative technologies with the ability to control not only from a stationary dispatching console but also with the ability to monitor and control remotely from a mobile device. An innovative service-digital approach to the management of engineering systems of buildings is fully revealed when using modern services, applications, mobile devices. [11]

In different sources you can find the information about the cost of engineering systems with the above dispatching capabilities which can range from 30 to $50 \%$ of the total cost of the real estate object. Additionallyy it is mentioned that the cost of the innovative digital components which include not only sensors, controllers, analyzers but also software (services and applications) can reach $5-7 \%$ of the cost of the engineering systems they manage. [10, 11]

The authors of this work note that concept of the service-digital approach to the management of engineering systems of buildings implies the use of the innovative servicedigital methods of control over the following engineering systems of the object as:

- $\quad$ heating system of various types;

- water supply system, utility-drinking and fire-fighting water system, system for collecting and filtration of surface water, systems for plantations irrigation;

- $\quad$ electricity supply system including power generation and accumulation system;

- $\quad$ security system including access system;

- microclimate formation system; 
- multimedia system and radio communication points;

- centralized and individual drainage waste system;

- $\quad$ waste utilization and disposal system. $[5,13]$

The above list shows that various engineering systems are used in the real estate objects and they are not often interconnected by functional dependencies, operating autonomously or interacting with resource-supplying organizations, therefore, for their operational management and monitoring the serviceability of the elements it is reasonable to band them in a single engineering complex controlled from a single dispatching point taking into consideration the service-digital approach.

The qualified and failure free operation of the modern engineering systems of the real estate objects is impossible without the involvement of competent service personnel - service specialists who should have the necessary scope of competence sufficient to ensure the estimated indicators for the functioning of the corresponding engineering systems. [14]

Based on the afore going it can be said that operation of the real estate objects and also intelligent buildings includes different types of activities which in one form or another represent the service providing - services for maintaining the operative condition of the objects, services for supplying the object with various resources, services for maintaining the engineering systems of the object and others.

Thus, on commissioning the construction object its future and service life depends on the quality of the services which are necessary for its operation. There is a strong interconnection between the real estate management processes and the processes related to the service activities. As it is known the service activities can be aimed at the end consumer - a private entity or a legal entity. [7] In both cases the customer is interested in high quality of the services which comply with the provisions of the contract or requirements of the effective regulations, technical conditions and rules.

As it follows from the above within the growth of the digital economy and formation of a new technological paradigm - transition to the service-digital economy in the service sector including the real estate objects management, it is necessary to possess such tools which will ensure the functioning of the optimal management model represented in the forms convenient for the customer, providing the transparency of the business activities and the safety of the service for both the customer and the contractor. $[2,3,5,11]$

\section{Methods}

When defining the optimal form of the model for the engineering systems management during the operation of the real estate objects it should be taken into consideration that these engineering systems are quite complex both from technical and from the managerial points of view and have internal links for interaction between subcomponents - subsystems as well as links for interaction with each other. Among other things such model should consider various aspects in terms of convenience, transparency and safety of the business activities and also qualification of the service personnel.

The engineering systems of the buildings are complex systems with rather severe input conditions. In the research [15] the authors propose in order to understand the management model of such systems to present the structure of the interconnection of the systems and subsystems in a unified information field applicable to a particular real estate object. In order to solve the task related to the complex interaction in the technical systems and subsystems the researchers Mokhov A.I., Mokhova L.A., Komarov N.M., Novozhenov S.G. propose to use the systems engineering and the complex engineering methods which allow to get an objective picture of the interaction of the systems and subsystems, determine the control capacity of such systems, better understand the functions and connections of the systems. 
The above approach allows solving the complex tasks typical for the engineering systems of the buildings in which there is an interaction of both information and physical links that ensure the functioning of the engineering systems. In the researches $[15,16]$ the authors give the methodology for the systems engineering and the complex engineering for considering the interaction of such systems.

The current level of the computer technology suggests that the modern innovative digital technologies allow to control and manage most of the components of the engineering systems. Such functionality is provided by a wide range of different sensors, devices, servo drives that perform tasks formulated by the control center. For the convenience of establishing the systems such components are called "Data points". In this case when constructing a diagram of the interaction of the system components not individual components are mentioned but the data points. When creating the control models at the stage of the systems design each such point can be endowed with the managing or controlling properties depending on the tasks which are reflected in the design specification. The number of such data points can reach several thousand while the dispatcher can efficiently manage the entire scope of the components solving the problem of the effective management of the engineering systems of the buildings.

\section{Discussion and results}

In respect to the management systems for the real estate objects engineering systems the scheme of interactions between technical systems discussed above can be presented in the form of model shown on Figure 1.

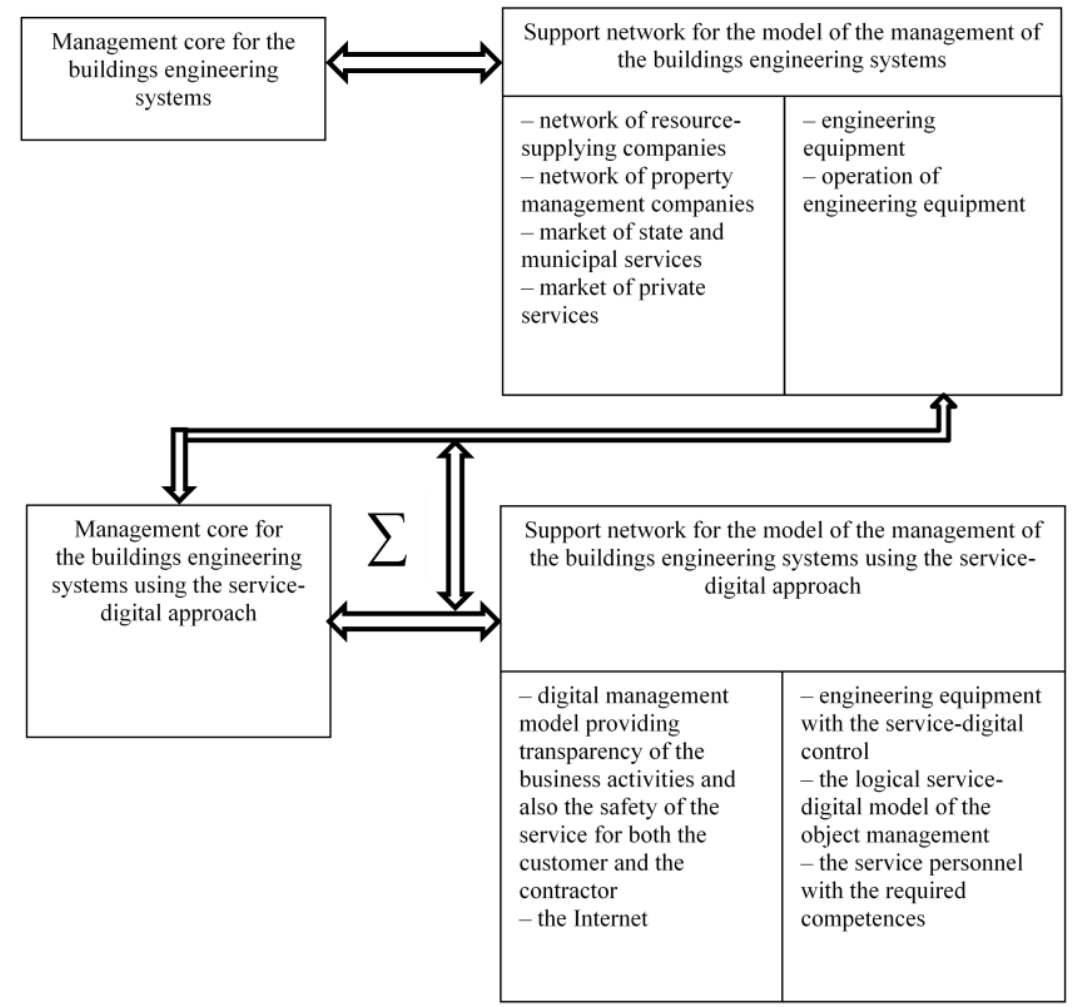

Fig. 1. The control model of the formation of the management core support network of the buildings engineering systems using the service-digital approach 
The figure shows the structural relation of the formation of the support network for the management core of the engineering systems of the buildings by means of the service-digital approach.

It is shown that the existing support network for the model of the management of the engineering systems of the buildings does not take into account the specifics of the modern conditions of the digital economy development, the innovative process taking place in these conditions and the formation of a new technological paradigm - the transition to the servicedigital economy. This model illustrates that in the modern conditions the management of the engineering systems of the building and the real estate objects in general are part of the service sector and due to this it is necessary to define theoretically-methodological aspects of management of the engineering systems of the real estate objects in order to update the management models demonstrated in the convenient for the customer forms which provide transparency of the business activities and also the safety of the service for both the customer and the contractor which requires the formation of a logical management model based on synthesized algorithms using a new innovative tooling for Russia - digitalization of the service sector which will allow the entities providing services in different sectors of the national economy to timely adopt to the innovative changes appearing in the economy of the Russia Federation in the face of developing of the digital economy and formation of a new technological paradigm - transition to the service-digital economy in solving this task. [17]

Mokhov A.I., Mokhova L.A., Komarov N.M., Novozhenov S.G. note that the model presented in Figure 1 can be referred to as the systems engineering model since it reflects the specific tasks of unifying and integrating the various systems in a single management system which is sufficiently understandable for study and analysis.

These authors specify that these models illustrating the interaction of the control and technical systems intended to unify them into a single system are also referred to as the complex engineering models. It should be noted that the effective interaction and control of the interaction of the participants which create core support network for the management of the buildings engineering systems is more effective using the service-digital.

\section{Discussion}

In a number of literature sources besides the reference to the information modeling one can also find the infographic modeling which was thoroughly reviewed in the research [18] using the example of automation systems modeling.

The first type of models reflects all the available information about the object while the second type of models is created based on the used part of the information about it. Both models have advantages and disadvantages. The advantages of the infographic models include the fact that they allow to develop and offer the personalized service and the package of services to the customer e.g. differentiated, personalized allocation or supply of resources to the objects depending on the time of year, season or the object workload using the ability to control the systems by the above data points. [19]

In addition to the above methods the approach which is mentioned in the research [20] and refers to the systems engineering can also be mentioned within the scope of the considering theme. This approach is based on the postulate of the systems engineering about the laws of organization and functioning of the complex social, natural, and technological systems. The general principles and evolutionary laws of the development of these systems are used which are projected onto the studied models of the systems interactions.

Mokhov A.I., Komarov N.M., Novozhenov S.G. in the research [20] say that the solution of such tasks from a mathematical standpoint is complicated by the fact that some processes and connections cannot be correctly expressed using separate variable values and the solution 
of these tasks is reduced to equations with many variables, however, simplifications lead to a significant scatter of the values of the calculation results.

Thus, solving one task, the researchers are faced with the need to solve additional tasks associated with a clear definition of the patterns of the interaction and functioning of the object's systems.

On making the comparative analysis of the mentioned methods we can say that they are not of equal importance within the scope of this article. The authors of this article think that it is advisable to make the final conclusions about the preference of one or the other method after comparing them in relation to a specific object.

According to the authors of this article the use of the above methods for modeling the management of the engineering systems of the buildings while designing the real estate objects in the context of the digitalization of the economy is a priority task and demands the use of a new, innovative service-digital approach in the construction, operation, and life cycle management of an object.

\section{Conclusion}

The problem of concept of the innovative service-digital approach in the management of engineering systems of buildings which is being reviewed in this article is quite complex and represents a combination of economic, technical, organizational, managerial relations in the management of the engineering systems of the real estate objects that arise in the process of forming a new technological paradigm in the context of growth of the digital economy.

In the face of the economy digitalization and growth of the service, maintenance component especially at the stage of operation of a real estate object, according to the authors of this article, we can talk about an evolutionary change in the management of the engineering systems of the buildings from the digital to the service-digital as evidenced by the fact that for the management it is necessary to involve the service specialists with the competencies enough to maintain the modern engineering systems, the increased requirements of the renters to the quality of the providing services by the property management companies or by the owners of the real estate objects and other factors. The above-said proves that in modern conditions of a tough competition for the client it is necessary to apply different tools and approaches when cooperating with the renters of the real estate objects.

One of these tools can be the use of the innovative service-digital approach in the management of engineering systems of buildings which will allow reaching the functioning of the optimal management model represented in the forms convenient for the customer, providing the transparency of the business activities and the safety of the service for both the customer and the contractor.

According to the authors of this article in order to solve this task one should formulate a logical management model based on the synthesized algorithms using a new innovative tooling for Russia - the digitalization of the service sector.

In the article as such tool various methods for solving this assigned task have been reviewed and they can be applied within the innovative concept of the service-digital approach. First of all, infographic models are to be applied in this respect.

When creating an infographic model of the management of engineering systems of buildings during the implementation of concept of the service-digital approach it is necessary to formulate the steps that will go from the customer to the contractor and help to introduce this concept. These steps can include the following:

- virtual modeling of an object or system;

- based on the virtual image record the main parameters and characteristics of the achieved system in the form of an infographic model; 
- convert the infographic model into an object which is suitable for processing in the graphic and text editors;

- using the resulting model to prepare a technical specification for design or modernization of an object, model or system in maximum detail;

- assess the technical specification from the point of view of concept of the service-digital approach;

- ensure the implementation of the resulting model with the involvement of the qualified specialists with the necessary set of competencies.

Based on the above analysis of concept of the innovative service-digital approach to management of engineering systems of buildings we can say that this concept requires to develop the theoretical model of the management in different industries where services are provided reflecting the influence of the computerization and digitalization of the economy and the society during the transition to the service-digital economy for what the methods discussed in this article can be used.

\section{References}

1. World Development Indicators: Structure of output. URL: http://data.worldbank.org/ data-catalog/world-development-indicators. Access date: 06.02.2021.

2. Evmenov A.D., Bulochnikov P.A., Blagova I.Y. Strategic planning of the innovative development of the service sector / Journal of Legal and Economic Studies, 2013, 4: pp.203-210. (2013)

3. Tulinov A.B., Goncharov A.B., Korneev A.A. Development strategy of industrial service in Russia / Theoretical and practical problems of service, 2008, No. 3 (28): pp.50-54. (2008)

4. Kuchin B.L., Yakusheva E.V. Management of economic systems development: technical progress, stability / Moscow: Economy, 1990, 157 pp. (1990)

5. Zharov V. G. Aspect of service company operation at early stages of market development / REVISTA INCLUSIONES ISSN 0719-4706 - Volumen 7 / Número Especial / Julio Septiembre $2020 \quad$ pp.29-40 http://revistainclusiones.com/gallery/3\%20VOL \%207\%20NUM\%20ESPECIAL\%20CI ENCIASENTIEMPODECAMBIOS\%20JULIOSEPTIEMBREEE2020REVINCLUSIO O.pdf Access date: 07.02.2021

6. Russia's innovative development strategy to 2020 (approved by the Decree of the Chairman of the Russian Government dated 08.12.2011 No. 2228-p / Rossiyskaya Gazeta, 2009, March 9, No. 4864. (2009)

7. Karpova G.A., Sushchinskaya M.D. Service sector in the modern economy / edited by SPb: Publisher SPbGEU, 2016, 114 pp. (2016)

8. Bokareva, E.V., Silaeva, A.A., Sokolova, A.P., Atamanova, M.A., Zudenkova, S.A. // The world oil market and its influence on Russian economy (2020) Smart Innovation, Systems and Technologies, 138, pp. 568-578.

9. Komarov N.M., Zharov V.G. Management of the intelligent building engineering systems using the information and infographic modeling / Service plus, 2003, No. 2, 74-81 pp. (2013)

10. Demenev A.V., Lopatko R.N., Zharov V.G. // Operation of Buildings and Structures Based on BIM Standards in the Digital Economy (2019) 2019 International MultiConference on Industrial Engineering and Modern Technologies, FarEastCon 2019. 
11. Teodorovich N.N., Mokhov A.I. To the question of the components and functional peculiarities of the security of the "Smart city" projects / In the publication of collected works: Evolutionary processes of information technologies. Collection of works based on the materials of the $4^{\text {th }}$ international scientific and technical conference. Under the general scientific editorship of Artyusheko V.M., Volovach V.I., 2019, 97-103 pp. (2019)

12. Butkevich M.N., Roganov A.A., Zharov V.G., Krivosheeva T.M., Teodorovich N.N., Kruglov O.A., Kiseleva A.V.

13. Development of the concept of the intelligent building for hotel industry / Research report (Ministry of Education and Science of the Russian Federation). (2013)

14. Sumzina L.V., Maksimov A.V., Zharov V.G. On the need for applying the assessment methodology of the service companies effectiveness / Industrial service, 2019, No. 4 (69), 33-36 pp. (2018)

15. Komarov N.M., Ivanov N.V., Safronov V.M., Zharov V.G., Duntsova N.V., Komarov K.N. Analysis of the competencies of the cognitive specialists that provide the growth of the human capital of the service companies / Internet journal Naukovedeniye, 2013, No. 1 (14), 30 pp. (2013)

16. Mokhov A.I., Mokhova L.A., Komarov N.M., Novozhenov S.G. Applied serviceology: the use of the systems engineering and the complex engineering modeling / Internet journal Naukovedeniye, 2012, No. 4 (13) URL: http://naukovedenie.ru/PDF/73evn412.pdf. Access date: 09.02.2021.

17. Komarov N.M. Influence of the high technology phenomenon on the development of the management / Intellect. Innovations. Investments, No. 4(1)-2011. (2011)

18. Komarov N.M., Zharov V.G. The concept of redesigning the energy efficiency management of the intelligent building / Service in Russia and abroad, 2013, No. 7 (45), 36-47 pp. (2013)

19. Latyshev G.V., Latyshev K.V., Mokhov A.I., Chulkov V.O. Infographic modeling of automation systems based on the circuit engineering of their elements / Electrical and information complexes and systems, 2012, No. 1 (volume 8), 3-9 pp. (2012)

20. Chulkov V.O. Infographic is a method and mean of forming and researching the functional systems / Bulletin of the International Academy of Science (Russian section), 2008, No.1, 46-51 pp. (2008)

21. Mokhov A.I., Komarov N.M., Novozhonov S.G. Application of the S-shaped theory to optimize the management of the high-tech companies / Internet journal Naukovedeniye, 2012, No.4 (13). (2012) 